\title{
Effect of naturally formed oxide films and other variables in the early stages of Mg-alloy corrosion in $\mathrm{NaCl}$ solution
}

Sebastián Feliu (Jr) ${ }^{a}$, C. Maffiotte ${ }^{b}$, Juan Carlos Galvánª, Violeta Barranco ${ }^{a, c}$.

${ }^{a}$ Centro Nacional de Investigaciones Metalúrgicas CSIC, Avda. Gregorio del Amo 8, 28040 Madrid, Spain, (e-mail: sfeliu@cenim.csic.es), (e-mail: jcgalvan@cenim.csic.es)

${ }^{\mathrm{b}}$ CIEMAT. FNL (edificio 2), Avda. Complutense, 22, 28040 Madrid, Spain (e-mail: cesar.maffiotte@ciemat.es)

Instituto de Ciencias de Materiales de Madrid, ICMM, Consejo Superior de Investigaciones Científicas, CSIC, Sor Juana Inés de la Cruz, 3, Cantoblanco, 28049, Madrid, Spain

Corresponding author: Tel.:+34 91 5538900. Fax.: +34 91 5347425. Email address: sfeliu@cenim.csic.es

\section{Abstract}

This paper studies the possible dependence of corrosion performance on surface conditions for $\mathrm{Mg}$ alloy specimens in $0.6 \mathrm{M} \mathrm{NaCl}$ solution. EIS measurements are used to compare the corrosion resistance of surfaces immediately after polishing, after months of ageing in air exposure, and in the as-received condition. Considering the evolution of the capacitive arc diameter of the Nyquist diagram, the surface conditions are seen to have an effect only in the early stages of testing. Other notable features include a marked tendency of the capacitive arc to decrease with immersion time in the case of the AZ61 alloy; a moderate tendency of this arc size to increase from the start of the test with the AZ31 alloy, and the evolution of the capacitive arcs towards practically steady state sizes with immersion time in the case of both alloys. These results seem to be caused by the offsetting of two opposing factors: the blocking of pores in the air-formed film by corrosion products, and the attack and/or transformation of the film by the saline solution. Stabilisation of the arc size by extending the immersion time reflects the attainment of a dynamic balance between corrosion and continuous film reconstruction processes. 
Keywords: Magnesium alloys ; Aluminium; Chloride; Electrochemical impedance spectroscopy; X-ray photoelectron spectroscopy 


\section{Introduction}

Magnesium and its alloys, especially Mg-Al alloys, have aroused great scientific and technological interest over the last two decades. From a practical point of view, magnesium is the lowest density structural metal, making it attractive for use in the automotive, aerospace, IT and electronics industries, and in the development of new biomaterials for orthopaedic and cardiovascular applications, where weight plays a decisive role. However, being one of the most chemically active metals, the use of magnesium is sometimes limited by its inadequate resistance to atmospheric and aqueous corrosion. There is a need for more complete information on the factors that influence the corrosion of these materials, and the present work aims to contribute to this knowledge.

The effect of aluminium as an alloying element to improve the corrosion resistance of magnesium has been studied in a wide range of experimental conditions, such as exposure to dry oxygen [1, 2], ambient atmospheres [3-5], atmospheres with a high degree of humidity [6-10], in immersion in distilled water [11], in saline solutions or atmospheres [12-27], etc. In Mg-Al alloys the greater oxygen affinity of aluminium tends to produce passivating aluminium oxide films or mixtures of $\mathrm{Mg}$ and $\mathrm{Al}$ oxides, which make the exposed surface especially stable [14-17].

Many researchers have carried out studies to find relationships between the alloy microstructure (amount and distribution of $\beta$-phase precipitates) or the Al content in the bulk alloy and its corrosion resistance [6-28]. A much smaller number of researchers have studied the effect of the thin passivating layers on the outer surface of the metal, which are formed in contact with the atmosphere or in solutions of low aggressivity [1$5,29,30]$.

Metals normally oxidise rapidly when exposed to oxygen. However, after just a short time (i.e. a few minutes), when a very thin oxide layer has formed, the reaction virtually ceases. Some time ago Cabrera and Mott [31] attributed the formation of this film to the effect of a strong electric field in the oxide associated with the presence of oxygen ions adsorbed on the outer surface of the metal. In a very thin film the electric field is enormous, but as the film thickens the effect of the electric field is reduced and the growth rate soon falls to a very low value. 
The thickness of the film formed in air on magnesium-based materials is initially around 2-3 nm, and can slowly increase up to some 4-7 nm after months of exposure at room temperature $[1,3,4,30,32]$. The surface composition of this oxide film can change significantly during ambient storage. Extra layers of hydrated and carbonated products of the magnesium oxide can be added to the original oxide film [1, 3, 32], and an increase in water molecules in the film has been reported for long ambient exposure times [33]. Hydrophobic organic-matter can also be picked up from the atmosphere [ 3 ]. Changes have been observed in the film growth rate depending on the nature of the compounds that form the film, e.g. the presence of a crystalline $\mathrm{Mg}(\mathrm{OH})_{2}$ after long exposure times [30].

Besides the influence of exposure time, composition and environmental conditions, film properties also depend on the tested alloy, in particular its microstructure and the presence of precipitates and inclusions [34]. In fact, the precise nature and properties of passivating films on the surface of $\mathrm{Mg}$ alloys formed in air or in aqueous solution is still open to debate.

Oxide film formation, and properties such as protectiveness, may be sensitive to the conditions in which they form. Laboratory tests normally refer to the behaviour of surfaces that are mechanically polished prior to testing, for metallographic observation and to remove impurities and corrosion product layers formed during storage. It is of theoretic and practical interest to know to what extent these experimental results are dependent on the characteristics of the spontaneously formed oxide film. With these ideas, the present research compares corrosion resistance results obtained for freshly polished surfaces, on which immediately tends to form the oxide film, to polished surfaces that have been aged for six months, and surfaces just in the as-received condition. The tests have focused on the aluminium-containing magnesium alloys AZ31 and AZ61, with approximately 3 and $6 \% \mathrm{Al}$, respectively. As is known, the aluminium content and microstructure are important factors in the corrosion behaviour of $\mathrm{Mg}-\mathrm{Al}$ alloys [23, 27, 35]; the microstructure of the AZ31 alloy is formed practically by an $\alpha-$ matrix with $\mathrm{Al}$ in solid solution, while a large part of the $\mathrm{Al}$ in the microstructure of the AZ61 alloy is precipitated in the form of $\beta$-phase (Fig. 1). The corrosion medium was a $0.6 \mathrm{M}$ solution of sodium chloride at ambient temperature. It has been especially interesting to observe the differences in behaviour during the first days of testing, when the effect of the oxide film is most clearly distinguished. 


\section{Experimental}

2.1. Materials. The chemical compositions of the tested magnesium alloys, $A Z 31$ and AZ61, are listed in Table 1. They were fabricated in wrought condition and supplied in plates of $3 \mathrm{~mm}$ thickness by Magnesium Elecktron Ltd.

2.2 Surface conditions. The research compares the behaviour of representative specimens of the above alloys in the following surface conditions: specimens in the original (as-received) surface state; freshly polished specimens; and polished specimens stored up to 6 months in the laboratory atmosphere at room temperature and $30-50 \%$ relative humidity.

2.3. XPS analysis. Photoelectron spectra were acquired with a Fisons MT500 spectrometer_equipped with a hemispherical electron analyser (CLAM 2) and a nonmonochromatic magnesium Ka X-ray source operated at $300 \mathrm{~W}$. The specimens were mechanically fixed on small flat discs supported on an XPZ manipulator placed in the analysis chamber. The residual pressure in this ion-pumped analysis chamber was maintained below $10^{-8}$ Torr during data acquisition. Spectra were collected for $20-90$ min., depending on the peak intensities, at a pass energy of $20 \mathrm{eV}$, which is typical of high-resolution conditions. The intensities were estimated by calculating the area under each peak after smoothing and subtraction of the S-shaped background and fitting the experimental curve to a mix of Lorentzian and Gaussian lines of variable proportion. Although specimen charging was observed, it was possible to determine accurate binding energies (BE) by referencing to the adventitious $\mathrm{C} 1 \mathrm{~s}$ peak at $285.0 \mathrm{eV}$. Atomic ratios were computed from peak intensity ratios and reported atomic sensitivity factors [36]. The sampled areas were $1 \times 1 \mathrm{~mm}^{2}$. The energy resolution is about $0.8 \mathrm{eV}$.

Bombardment was performed using an EXO5 ion gun incorporated in the equipment, provided with a scanning unit to track the beam and operating at a voltage of $5 \mathrm{kV}$, an intensity of $10 \mathrm{~mA}$ and a pressure of $1 \times 10^{-7}$ Torr. The sample current was $1 \mu \mathrm{A}$ during bombardment.

2.4. Metallographic characterisation. The specimens were dry ground through successive grades of silicon carbide abrasive papers from P120 to P2000 followed by finishing with $0.1 \mu \mathrm{m}$ diamond paste. The tested specimens were examined by 
scanning electron microscopy (SEM) using a JEOL JSM-6400 microscope equipped with Oxford Link energy-dispersive X-ray (EDX) microanalysis hardware.

2.5. AFM characterisation. Images of the specimen surfaces were obtained in original and polished condition using an atomic-force microscope (AFM). All images (20 x 20 $\mu \mathrm{m})$ were taken in the 5100 AFM/SPM from Agilent Technologies working in tapping mode using Si type AFM cantilevers with a normal spring constant of $40 \mathrm{~N} / \mathrm{m}$ and a typical radius of $10 \mathrm{~nm}$ from Applied Nanostructures. Images were acquired at a resolution of $512 \times 512$ points and subjected to first-order flattening. After flattening, the RMS roughness (root-mean-squared roughness) was calculated.

2.6. EIS measurements. Electrochemical impedance measurements were conducted in $0.6 \mathrm{M} \mathrm{NaCl}$ for different times up to 28 days at room temperature $\left(\sim 25^{\circ} \mathrm{C}\right)$ and $\mathrm{pH} 5.6$, although the $\mathrm{pH}$ evolved freely during the experiment. An AUTOLAB potentiostat, model PGSTAT30, with frequency response analyser (FRA) software was used. The frequency ranged from $100 \mathrm{kHz}$ to $1 \mathrm{mHz}$ with 5 points/decade, whereas the amplitude of the sinusoidal potential signal was $10 \mathrm{mV}$ with respect to the open circuit potential (OCP). A typical three-electrode set-up was employed: $\mathrm{Ag} / \mathrm{AgCl}$ and graphite were used as reference and counter electrodes, respectively, and the material under study was the working electrode.

\section{Results and discussion}

\section{1. Characterisation of the natural oxide film}

XPS data clearly shows that the surface of the specimens is covered by an oxide layer of $\mathrm{MgO}$ with some magnesium hydroxide (Fig. 2). Table 2 shows the element composition obtained by XPS on the as-received and polished surfaces of the AZ31 and AZ61 alloys and its variation with sputtering time. Attention is drawn to the presence of a significant amount of calcium on the original (as-received) surfaces of both alloys, which disappears after surface polishing. In general, $5 \mathrm{~min}$. of sputtering (shortest sputtering time tested) is seen to be sufficient to remove the calcium content detected on the original alloy surfaces. This calcium probably forms part of the composition of mixed oxides and carbonates in the outermost stratum of the oxide film. 
The $\mathrm{O} /(\mathrm{Mg}+\mathrm{Al})$ atomic ratios obtained on the non-sputtered surface of the original AZ31 and AZ61 alloys reach values close to 1.6 (Table 2), which tends to suggest that the surface of the specimens is covered by a thin oxide layer of $\mathrm{Mg}(\mathrm{OH})_{2}$ with some aluminium oxide. On the non-sputtered surface of the polished alloys this ratio reaches values of close to 3 . The spontaneous formation of magnesium carbonate on the freshly polished surfaces presumably accounts for this increase. After $5 \mathrm{~min}$. of sputtering, significant amounts of aluminium appear in the oxide film, especially with the AZ61 alloy.

On the sputtered surface of the polished AZ31 and AZ61 alloys, a considerable increase in the magnesium content is seen to coincide with a decrease in the oxygen content (Table 2). Five min. of sputtering is sufficient to remove the significant carbon content detected on the surface of the alloys. The thin outer film of magnesium oxides formed as a result of the polishing process is probably uniform, homogeneous and continuous. In contrast, no great variation in the magnesium or oxygen contents is detected on the original surface of the AZ31 and AZ61 alloys when the sputtering time is raised from 5 to 10 minutes, and the presence of carbon is noted after 10 minutes of sputtering. These results tend to suggest that the external oxide film resulting from the fabrication of the wrought alloys has a non-uniform distribution (e.g., in the form of islands) over the alloy surface and is discontinuous and porous. AFM images (Fig. 3) tend to support this interpretation. The $\mathrm{O} /(\mathrm{Mg}+\mathrm{Al})$ ratios between 1.6 and 1.2 obtained on the sputtered surface of the original $A Z 31$ and $A Z 61$ alloys reflect the existence of an outer layer comprised by a mixture of $\mathrm{MgO}, \mathrm{Al}_{2} \mathrm{O}_{3}$ and maybe by $\mathrm{MgAl}_{2} \mathrm{O}_{4}$.

XPS determinations of the oxide film thickness (Table 3) yield different values for each type of alloy, the superficial film formed on the polished AZ61 alloy being some $2 \mathrm{~nm}$ thicker than on the AZ31 alloy. The presence of a coarse discontinuous outer layer of magnesium and aluminium oxides on the surface of the AZ31 and AZ61 alloys in their original state has prevented, in this case, similar estimates of native oxide film thickness.

As Table 4 shows, the roughness values of the specimens in the original conditions is about ten times greater than in the polished condition. Nanometric scale details of the typical surface roughness exhibited by the tested specimens are given in Fig. 3 .

\subsection{Capacitive loop and $R_{H F}$ values}


The evolution of the corrosion process has been monitored by means of EIS measurements with the specimens immersed in $0.6 \mathrm{M} \mathrm{NaCl}$ solution. Bode plots of the phase angle $\delta$ (Fig. 4) show the existence of two time constants, which in the Nyquist diagrams mean the presence of a capacitive loop at high frequencies (HF) and an inductive loop at low frequencies (LF). In the literature on the behaviour of magnesium and its alloys, the capacitive loop in the HF region has been always attributed to the charge transfer reaction of the corrosion process $[25,27,35,37,38]$. The diameter of the HF loop ( $\left.\mathrm{R}_{\mathrm{HF}}\right)$ is inversely related to the corrosion rate by means of the Stern-Geary equation [39]. The inductive arc at low frequencies has been attributed in the literature to processes not directly related with the corrosion rate, such as adsorption/desorption processes, and especially in the case of magnesium, to the presence of the intermediate $\mathrm{Mg}^{+}$and its transition into a divalent ion [12,14, 23, 40].

Assuming the electrochemical behaviour of the capacitive loop to be represented by a parallel combination of resistance and capacitance elements, the value of $R_{H F}$ linked to the corrosion process resistance has been estimated. Despite the differences in the impedance diagrams obtained in repeated tests, and the fluctuations in the evolution of these diagrams with immersion time, some tendencies are apparent in the $R_{H F}$ values, which yield information on the effect of the studied variables.

\subsection{Effect of surface conditions}

Fig. 5 displays $R_{H F}$ values for the $A Z 31$ and $A Z 61$ alloy specimens tested. The evolution of $R_{H F}$ as a function of time reveals that surface conditions exert a certain effect during the initial stage of testing. Attention is drawn to the high $\mathrm{R}_{\mathrm{HF}}$ values for the AZ61 alloy specimens tested immediately after polishing (freshly polished surfaces). Mechanical polishing probably leaves the metallic surface in a specially active state that promotes the immediate growth of a more perfect protective oxide film than the films resulting from 6 months atmospheric storage or covering the as-received (original) surfaces .

\subsection{Effect of immersion time and alloy type}

The behaviour of the specimens during the first day of immersion presents certain traits that are not seen in exposure for longer times (Fig. 5). On the first day the predominant trend is for the $R_{H F}$ to increase with immersion time, especially in the case of AZ61 
alloy. An exception can be seen in the case of specimens dipped into solution immediately after polishing, which show practically constant $R_{H F}$ values throughout the first day. For times of more than 1 day up to approximately 10 days, the tendency for many specimens is the reverse, with a reduction in $\mathrm{R}_{\mathrm{HF}}$ with immersion time (Fig. 5).

The above differences in the evolution of $R_{H F}$ with immersion time may be due to the offsetting of two opposing effects: blocking of the pores in the pre-existing film with corrosion products and dissolution of this film by the saline solution. The relative weight of each effect cannot be estimated, so it is not possible to predict the results, although it may be supposed that the first effect will predominate at the start of testing and the latter will take precedence after about $24 \mathrm{~h}$ of immersion.

One point emerging in the set of $R_{H F}$ values (Fig. 5) is the clear tendency for alloy AZ61 to present higher values than the alloy AZ31 for the same immersion times. This greater resistance is in agreement with results reported in the literature, which indicate a beneficial effect of the higher Al alloying content on the corrosion resistance of $\mathrm{Mg}-\mathrm{Al}$ alloys [23].

After the first day of immersion, the $R_{H F}$ values of the $A Z 61$ alloy specimens show a marked tendency to decrease in time, an effect that continues up to approximately 10 days of immersion (Fig. 5). Curiously, with alloy AZ31 the reverse tendency seems to predominate, although its effect is much less notable. It is considered a relevant fact that the $\mathrm{R}_{\mathrm{HF}}$ values obtained with the two alloys converge in time towards relatively similar values.

This behaviour of the AZ61 and AZ31 alloys is best illustrated in Fig. 6, which shows the variations of average $\left\langle R_{H F}\right\rangle$ values with time for all the tested specimens. This representation is instructive in showing the predominant trends in the evolution of $<R_{H F}>$ values. At the start of the test attention is drawn to the high values for the $A Z 61$ alloy, which subsequently decrease with time, followed by the final tendency towards approximately constant values. In contrast, alloy AZ31 starts with values that are initially notably lower and tend to grow moderately with time until also reaching an approximately constant level. Throughout the graph, the AZ61 alloy exhibits higher $\mathrm{R}_{\mathrm{HF}}$ values than AZ31, although the differences are smaller after about 20 days of immersion. Since stationary $\left\langle R_{H F}\right\rangle$ values take a significant time to become established, i should be noticed that short-term measurements may give rise to 
misleading comparisons of corrodibility without specifying the time during which alloys AZ31 and AZ61 have been immersed in the aggressive solution.

\subsection{Changes in surface films during immersion time}

The above results are logically linked to changes experienced by the specimen surfaces during exposure to the $0.6 \mathrm{M} \mathrm{NaCl}$ solution. In this respect, the following features are highlighted: (i) the marked tendency of the AZ61 alloy for the capacitive arc size to decrease with immersion time from the first day; (ii) the moderate tendency of the AZ31 alloy for the capacitive arc size to grow from the start of the test; and (iii) for longer immersion times, the evolution of the capacitive arc to a practically steady state size with both alloys. In case (i), the decrease in the capacitive arc size with time suggests a weakening of the protective action of the film or films coating the metallic surface, probably due to progressive dissolution or deterioration of the air-formed film in contact with the aggressive $0.6 \mathrm{M} \mathrm{NaCl}$ solution. Various studies [11, 16, 19, 20, 25, 28-30] on the behaviour of $\mathrm{Mg}$ and its alloys in immersion tests mention the presence of a very thin $\mathrm{MgO}$ film of a constant thickness (just a few nanometres) on the metallic surface, whose occurrence is probably related to the Cabrera-Mott mechanism of film growth [4]. These studies also note the additional formation of an outer layer of corrosion products that can extend to a significant distance from the metallic surface. It is known that magnesium dissolution favours the production of $\mathrm{OH}^{-}$ions from the cathodic reaction, increasing the $\mathrm{pH}$ and allowing the formation of a magnesium hydroxide film by means of a precipitation reaction $[1,12]$. Several studies mention the formation of coarse corrosion product layers, composed mainly of $\mathrm{Mg}(\mathrm{OH})_{2}$, on the surface of $\mathrm{Mg}$ and its alloys immersed in aqueous solutions [1, 11, 20]. The thickness of these films can reach up to $15-200 \mu \mathrm{m}$ after 10 days of immersion in $0.6 \mathrm{M} \mathrm{NaCl}$ solution [1].

Since the films formed in an aqueous environment are not equal to the films formed in air, once a specimen is placed in solution the pre-existing film on its surface may be transformed, reconstructed, or replaced by a new film. In case (i) the effect of all these possible processes obviously cannot compensate the weakening of the film resistance. In case (ii), the increased capacitive arc size with immersion time suggests a reinforcement of the protective action of the films coating the metallic surface. On alloy AZ31 the initial film may be of little protective power and its effect on the specimen's 
behaviour will tend to disappear relatively quickly, a leading role may soon be taken by the new films formed as a result of the reaction with the aqueous medium, whose consolidation and growth must be attributed responsibility for the moderate tendency for the capacitive arc size to increase.

In case (iii) the practical equalling of the arcs corresponding to the different initial surface conditions with immersion time suggests the evolution of the specimens towards states of similar surface constitution and activity. When the immersion time increases from approximately 10 days to 28 days (maximum immersion time), the $R_{H F}$ value tends to a steady state value, which reflects the attainment of a dynamic balance between the corrosion and continuous film reconstruction processes. The drop in $R_{H F}$ values for alloy AZ61 and the increase for alloy AZ31 with immersion time are translated in Fig. 5 into a notable reconciliation of the points corresponding to both alloys after about 20 days.

\subsection{Capacitance values}

Fig. 7 displays the capacitance values associated with the capacitive loop of the impedance diagrams. Since there is some impedance frequency dispersion behaviour in the measurements, a constant phase element (CPE) was used to fit the experimental EIS spectra. Capacitance $(C)$ values were obtained from the relationship [41]:

$C=Q\left(\omega_{\max }\right)^{\mathrm{n}-1}$

where $\mathrm{Q}$ and $\mathrm{n}$ are the components of $\mathrm{CPE}$, and $\omega_{\max }$ is the frequency at which the imaginary part of the impedance has a maximum. Comparing the graphs for alloys AZ31 and AZ61 in Fig. 7, it can be seen that the capacitance values in the first $24 \mathrm{~h}$ of immersion are clearly higher in the case of the AZ31 alloy specimens than for AZ61. Subsequently, over the next 15 days, the capacitance values continue to be greater for AZ31, though tending to decrease, while the values for AZ61 tend to increase gradually, so that the values for both alloys converge on practically similar capacitance values. After 15-20 days, the capacitance values for all the tested specimens are grouped around $15-20 \mu \mathrm{F} / \mathrm{cm}^{2}$.

The higher initial values of capacitance for alloy AZ31 compared with alloy AZ61 ( Fig. 7) suggest either the presence of thinner films according to the inverse relationship 
between capacitance and film thickness of the flat capacitor formula [45], or more defective films which leaves a greater fraction of metallic surface area in contact with the electrolyte [46]. No significant differences in capacitance values have been observed as a function of surface conditions tested.

\subsection{Inductive loop}

As already commented, the impedance diagrams in this study are characterised by a capacitive loop at HF followed by a well-marked inductive loop at LF. Elucidating the precise nature of the inductive loop seems rather complicated and is of no practical relevance with regard to information on the corrosion rate. Nevertheless, the repeated presence of an inductive loop in the impedance diagrams obtained in this work merits some attention.

Numerous examples of such inductive loops can be found in the literature. An inductive effect may be explained by different reasons. It is normally related with the adsorption of active species on the metallic surface, whose coverage depends on the electrode potential variations during the measurements [15, 16, 20, 47-49]. In the corrosion of magnesium and its alloys, where $\mathrm{Mg}^{2+}$ ion production seems to occur in two steps, the intermediate $\mathrm{Mg}^{+}$should be the adsorbed specie $[16,20,50]$.

The notable size of the inductive loops in this work may be seen in Fig. 8. Their size seems to be related somehow with the $R_{H F}$ value and, therefore, with the surface activity of the specimens in the corrosive medium.

Immersion time has also been seen to have an effect on the relative size of the inductive loop. If the loop size is expressed as the diameter of the semicircle that fits it, and $\delta$ is the ratio between the diameters of the inductive and capacitive loops, after two hours of immersion $\delta$ values of the order of 0.7-0.8 have been obtained with practically all the tested alloys and surface conditions. At longer immersion times, between 1 and 28 days, the $\delta$ ratio continues to be of the order of 0.7-0.8 for alloy AZ31 but decreases significantly with alloy AZ61 to approximately 0.3-0.4. 


\section{Conclusions}

The corrosion behaviour of magnesium alloys $A Z 31$ and $A Z 61$ in several surface conditions has been studied by the EIS technique, trying to relate the experimental circumstances of the oxide film formation in the air with the subsequent behaviour of the alloy immersed in $0.6 \mathrm{M} \mathrm{NaCl}$ solution. Analysis of impedance diagrams has identified the presence of two different time constants: a capacitive loop at high frequencies, ascribed to the corrosion process; and an inductive loop at low frequencies, ascribed to the relaxation of adsorbed species. The following points may be emphasised:

(1) A certain effect of the surface condition is observed only in the initial stage of the test. Attention is drawn to the high capacitive loop diameter values $\left(R_{H F}\right)$ in the case of the specimens tested immediately after mechanical polishing compared to those tested after 6 months of exposure to the laboratory atmosphere or in the as-received condition. After this initial stage, which does not last for more than about 7 days, no effect attributable to the surface condition of the specimens is generally seen.

(2) With regard to the effect of the alloy type and immersion time variables, in the first days of immersion a clear tendency is observed for the highest $R_{H F}$ values to correspond to the AZ61 specimens. After 15 days of testing the differences between the AZ61 and AZ31 alloys are notably smaller, although the AZ61 alloy continues to show the largest arcs (lower corrosion rates).

(3) In the evolution of the $R_{H F}$ and capacitance values with time, a fundamental role must be attributed to changes undergone by the pre-existing air-formed film during immersion time and its replacement by other films that form in the aqueous solution.

(4). An evident effect of the alloy type but not of the surface condition on the capacitance values has been shown. Attention is also drawn to the difference in behaviour between the AZ31 and AZ61 alloys with regard to the inductive loop.

\section{Acknowledgment}

We wish to express our gratitude to Prof. S. Feliu for several clarifying and stimulating discussions during the course of this work. Also, the authors 
gratefully acknowledge the financial support for this work from the Ministry of Science and Innovation of Spain ( MAT 2009-13530)

\section{References}

[1] V. Fourier, P. Marcus, I. Olefjord, Sur. Interface Anal., 34 (2002) 494.

[2] J. Kim, K.C. Wong, P.C. Wong, S.A. Kunlich, J.B. Metson, K.A.R. Mitchell, Appl. Sur. Sci., 253 (2007) 4197.

[3] 3.C. Fotea, J. Callaway, M.R. Alexander, Sur. Interface Anal., 38 (2006) 1363.

[4] N.S. McIntyre, C. Chen, Corros. Sci., 40 (1998) 1697.

[5] J.H. Nordlien, S. Ono, N. Masuko, K. Nisancioglu, Corros. Sci., 39 (1997) 1397.

[6] S.J. Splinter, N.S. McIntyre, Surf. Sci., 314 (1994) 157.

[7] R. Lindstrom, J.E. Svenson, L-G. Johansson, J. Electrochem. Soc., 149 (2002) B103.

[8] R. Lindstrom, L-G. Johansson, G.E. Thompson, P. Skeldon, J-E. Svensson, Corros. Sci.,46 (2004) 1141.

[9] M. Johnsson, D. Persson, R. Gubner, J. Electrochem. Soc., 157 (2007) C684.

[10] M. Johnsson, D. Persson, D. Thierry, Corros. Sci., 49 (2007), 1540.

[11] J.H. Nordlien, S. Ono, N. Masuko, K. Nisancioglu, J. Electrochem. Soc., 10 (1995), 3320.

[12] G. Baril, N. Pebere, Corros. Sci., 43 (2001) 471.

[13] Ballerini, U. Bardi, R. Bignucolo, G. Ceraolo, Corros. Sci., 47 (2005) 2173.

[14] G. Song, A. Atrens, X. Wu, B. Zhang, Corros. Sci., 40 (1998) 1769.

[15] G. Song, A. Atrens, D. Stjhon, J. Naim, Y. Li, Corros. Sci.,39 (1997) 855. 
[16] J.H. Nordlien, K. Nisancioglu, S. Ono, N. Masuko, J. Electrochem. Soc., 143 (1996) 2564.

[17] J.H. Nordlien, K. Nisancioglu, S. Ono, N. Masuko, J. Electrochem. Soc., 144 (1997) 461.

[18] O. Lunder, J.E. Lein, T. Kr. Aune, K. Nisancioglu, Corrosion, 45 (1989), 741.

[19] G. Song, A. Atrens, M. Dargusch, Corros. Sci., 41 (1998) 249.

[20] R. Lindstrom, L.G. Johansson, J-E. Svensson, Mater. and Corros. , 54 (2003) 587.

[21] R. Ambat, N.N. Aung, W. Zhou, Corros. Sci., 42 (2000) 1433.

[22] S. Mathieu, C. Rapin, J. Steinmetz, P. Steinmetz, Corros. Sci., 45 (2003) 2741.

[23] G.L. Song, A. Atrens, Adv. Eng. Mat., 1 (1999) 11.

[24] G.L. Song, A. Atrens, Adv. Eng. Mat., 9 (2007) 177.

[25] G.L. Makar, J. Kruger, J. Electrochem. Soc., 137 (1990) 414.

[26] A. Pardo, M.C. Merino, A.E. Coy, R. Arrabal, F. Viejo, E. Matykina, Corros. Sci., 50 (2008) 823.

[27] A. Pardo, M.C. Merino, A.E. Coy, F. Viejo, R. Arrabal, S. Feliu Jr, Electrochim. Acta 53 (2008) 7890.

[28] G.L. Song, A, Atrens, Adv. Eng. Mater., 5 (2003) 837.

[29] S. Feliu Jr, A. Pardo, M.C. Merino, A.E. Coy, F. Viejo, R. Arrabal, Appl. Surf. Sci., 255 (2009) 4102.

[30] S. Feliu Jr, M.C. Merino, R. Arrabal, A.E. Coy, E. Matykina, Surf. Interface Anal., 41 (2009)143.

[31] N. Cabrera, N.F. Mott, Rep. Progr. Phys., 12 (1948) 163. 
[32] M. Jönsson, D. Persson, C. Leygraf, Corros. Sci., 50 (2008) 1406.

[33] C. Chen, S.J. Splinter, T. Do, N.S. Mclntyre, Sur. Sci., 382 (1997) L652.

[34] M. Santamaría, F. Di Quarto, S.Zanna, P. Marcus, Electrochim. Acta, 53 (2007) 1314.

[35] S. Mathieu, C. Rapin, J. Hazan, P. Steinmetz, Corros. Sci., 44 (2002) 2737.

[36] C.D. Wagner, L.E. Davis, M.V. Zeller, J.A. Taylor, R.H. Raymond, L. Gale, Surf. Interface Anal., 3 (1981) 211.

[37] N. Pebere, C. Riera, F. Dabosi, Electrochim. Acta, 35 (1990) 555.

[38] G. Song, A. Atrens, D. St. John, X. Wu, J. Nairn, Corros. Sci., 39 (1997) 1981.

[39] M. Stern, A.L. Geary, J. Electrochem. Soc., 104 (1957) 56.

[40] G.G. Perrault, J. Electrochem. Soc., 51 (1974) 107.

[41] F.Huet, M. Musiani, R.P. Nogueira, J. Solid State Electrochem. , 8 (2004), 786-793.

[42] H. Vogt (1983), in: E. Yeager, J.O.M. Bockris, B.E. Conway, E. Sarangapani (eds). Comprension treatise of electrochemistry, vol 6. Plenum, New York, p. 445.

[43] P.J. Sides (1986), in: R.E. White, J.O.M. Bockris, B.E. Conway (eds). Modern aspects of electrochemistry, Vol 18. Plenum, New York, p. 303.

[44] C.H. Hsu, F. Mansfeld, Corrosion, 57 (2001) 747.

[45] G. Baril, G. Galicia, C. Deslouis, N. Pebere, B. Tribollet, V. Vivier, J. Electrochem. Soc., 154 (2007) C108.

[46] V. Barranco, S. Feliu Jr., S. Feliu, Corros. Sci., 46 (2004), 2221.

[47] J. Epelboin, C. Gabrielli, M. Keddam, Electrochim. Acta, 22 (1975) 913. 
[48] W.J. Lorenz, F. Mansfeld, Corros. Sci., 21 (1981) 647-672.

[49] M. Metikos-Hukovic, R. Babic, Z. Grubac, J. Appl. Electrochem., 32 (2002) 34-41.

[50] G. Galicia, N. Pebere, B. Tribollet, V. Vivier, Corros. Sci., 51 (2009) 1789.

\section{Tables and figures}

Table 1. Bulk composition of the AZ31 and AZ61 alloys.

Table 2. Atomic composition of the surface of the AZ31 and AZ61 alloys in original (asreceived) and polished conditions.

Table 3. Thickness of air-formed oxide film on polished specimens.

Table 4. Roughness values obtained with atomic force microscopy. The values are the averages of four determinations.

Figure 1. SEM micrographs: (a) AZ31 alloy, (b) AZ61 alloy.

Figure 2. XPS Mg2p spectra of the AZ31 and AZ61 alloys in the original (O) and polished $(P)$ surface conditions.

Figure 3. AFM images of the surfaces in the original $(O)$ and polished $(P)$ surface conditions for: (a) AZ31 alloy and (b) AZ61 alloy.

Figure 4. Examples of impedance diagrams for the tested alloys. Nyquist and Bode plots (a) for alloy AZ31 and (b) for alloy AZ61.

Figure 5. Variation in $R_{\mathrm{HF}}$ values as a function of surface conditions and alloy type over 28 days immersion. 
Figure 6. Variation in average $\left\langle R_{H F}\right\rangle$ values with immersion time for the $A Z 31$ and AZ61 alloys.

Figure 7. Variation in capacitance values as a function of surface conditions, alloy type and immersion time.

Figure 8. Variation in Nyquist plots for (a) AZ31 and (b) AZ61 specimens with immersion time (hours and days on the $\mathrm{Y}$-axis), and surface conditions $(\mathrm{O}$, original surface; PE, six months after polishing; RP, freshly polished). 
Table 1. Bulk composition of the AZ31 and AZ61 alloys

\begin{tabular}{|l|l|l|l|l|l|l|l|l|l|l|}
\hline Material & $\mathrm{Al}$ & $\mathrm{Zn}$ & $\mathrm{Mn}$ & $\mathrm{Si}$ & $\mathrm{Cu}$ & $\mathrm{Fe}$ & $\mathrm{Ni}$ & $\mathrm{Ca}$ & $\mathrm{Zr}$ & Others \\
\hline AZ31 & 3.1 & 0.73 & 0.25 & 0.02 & $<0.001$ & 0.005 & $<0.001$ & 0.0014 & $<0.001$ & $<0.30$ \\
\hline AZ61 & 6.2 & 0.74 & 0.23 & 0.04 & $<0.001$ & 0.004 & $<0.001$ & 0.0013 & $<0.001$ & $<0.30$ \\
\hline
\end{tabular}

Table 2. Atomic composition of the surface of the AZ31 and AZ61 alloys.

Tabla 3 con los \% atómicos obtenidos en el XPS del CIEMAT

\begin{tabular}{|c|c|c|c|c|c|c|c|c|}
\hline & $\begin{array}{l}\text { Time of } \\
\text { sputtering } \\
\text { (min) }\end{array}$ & $\% \mathrm{C}$ & $\% O$ & $\% \mathrm{Mg}$ & $\% \mathrm{Al}$ & $\% \mathrm{Ca}$ & $\mathrm{O} /(\mathrm{Mg}+\mathrm{Al})$ & $\begin{array}{l}\mathrm{Al} /(\mathrm{Mg}+\mathrm{Al}) \\
\mathrm{X} 100\end{array}$ \\
\hline \multicolumn{9}{|c|}{ Original Surface } \\
\hline \multirow[t]{3}{*}{ AZ31 } & 0 & 51 & 30 & 16 & 2 & 1 & 1,6 & 11 \\
\hline & 5 & 5 & 53 & 38 & 4 & 0 & 1.25 & 10 \\
\hline & 10 & 4 & 52 & 38 & 6 & 0 & 1.2 & 14 \\
\hline \multirow[t]{3}{*}{ AZ61 } & 0 & 65 & 21 & 10 & 3 & 1 & 1.6 & 23 \\
\hline & 5 & 11 & 55 & 26 & 8 & 0 & 1.6 & 24 \\
\hline & 10 & 5 & 56 & 28 & 11 & 0 & 1.4 & 28 \\
\hline \multicolumn{9}{|c|}{ Polished Surface } \\
\hline \multirow[t]{3}{*}{ AZ31 } & 0 & 51 & 35 & 12 & 2 & 0 & 2.5 & 14 \\
\hline & 5 & 0 & 41 & 54 & 5 & 0 & 0.7 & 8 \\
\hline & 10 & 0 & 18 & 75 & 6 & 0 & 0.2 & 7 \\
\hline
\end{tabular}




\begin{tabular}{|l|l|l|l|l|l|l|l|l|}
\hline AZ61 & 0 & 37 & 47 & 13 & 3 & 0 & 3 & 19 \\
\cline { 2 - 9 } & 5 & 0 & 46 & 46 & 8 & 0 & 0.9 & 15 \\
\cline { 2 - 9 } & 10 & 0 & 21 & 68 & 11 & 0 & 0,3 & 14 \\
\hline
\end{tabular}

Table 3. Thickness of the air formed oxide film on polished specimens.

\begin{tabular}{|l|c|}
\hline Material & Film thickness $(\mathrm{nm})$ \\
\hline AZ31 & 3.2 \\
\hline AZ61 & 5.1 \\
\hline
\end{tabular}

Table 4. Roughness values obtained with atomic force microscope. The values are average of four determinations.

\begin{tabular}{|l|l|}
\hline SPECIMENS & RMS $(\mathrm{nm})$ \\
\hline ORIGINAL SURFACE & \\
AZ31 & 197.9 \\
AZ61 & 116.2 \\
AFTER POLISHING & \\
AZ31 & 29.1 \\
AZ61 & 17.1 \\
\hline
\end{tabular}




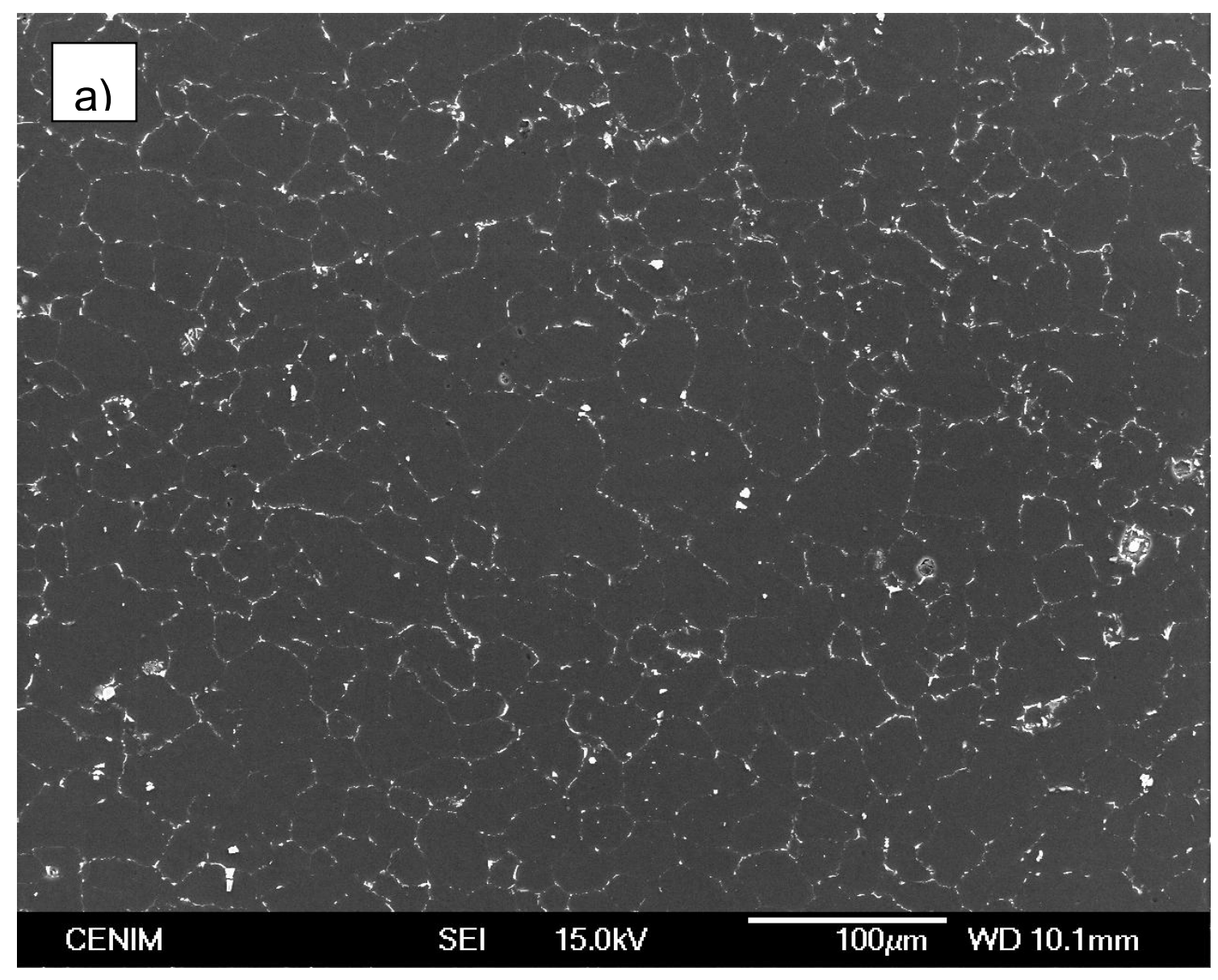

Fig 1(a) 


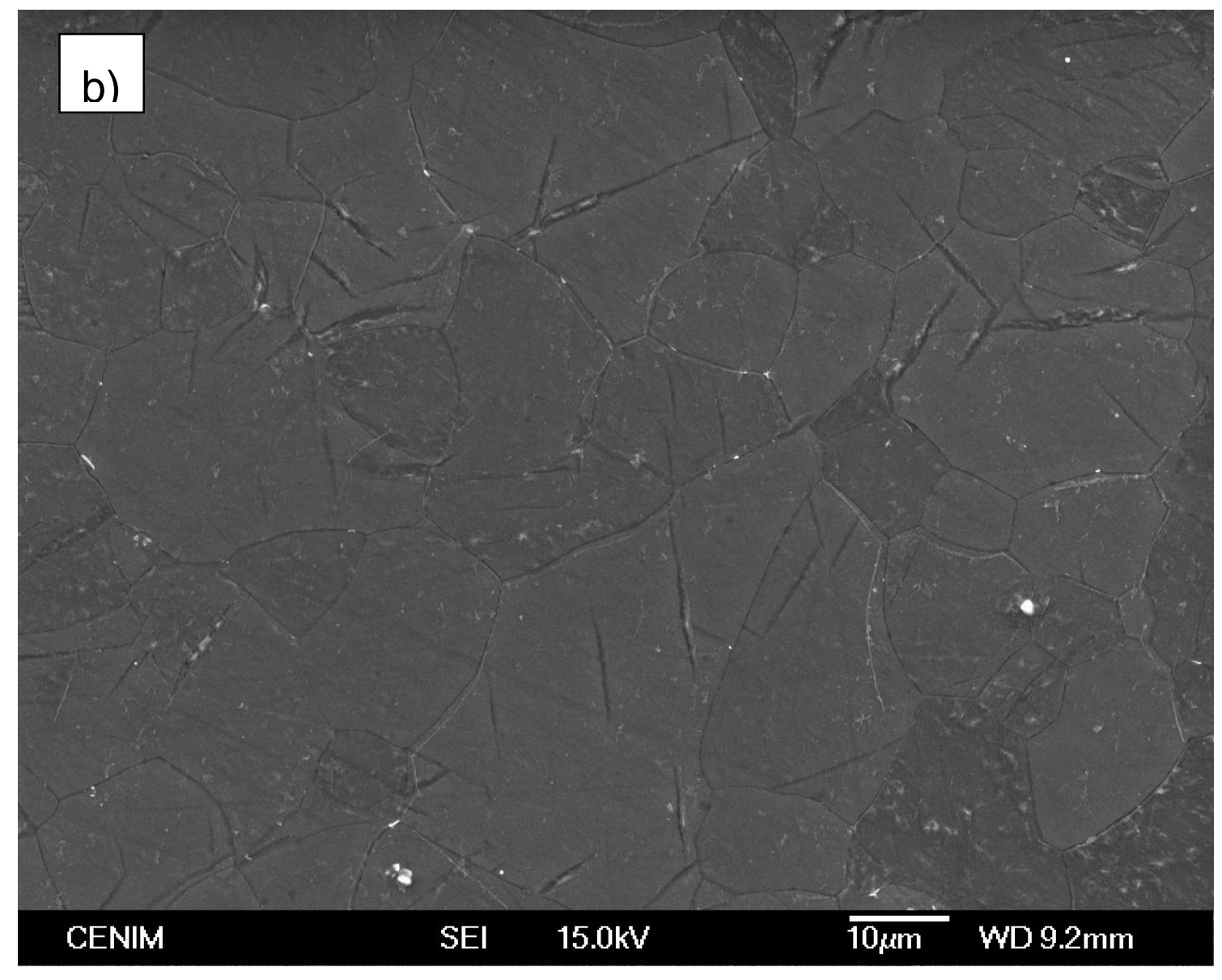

Fig $1 b$ 


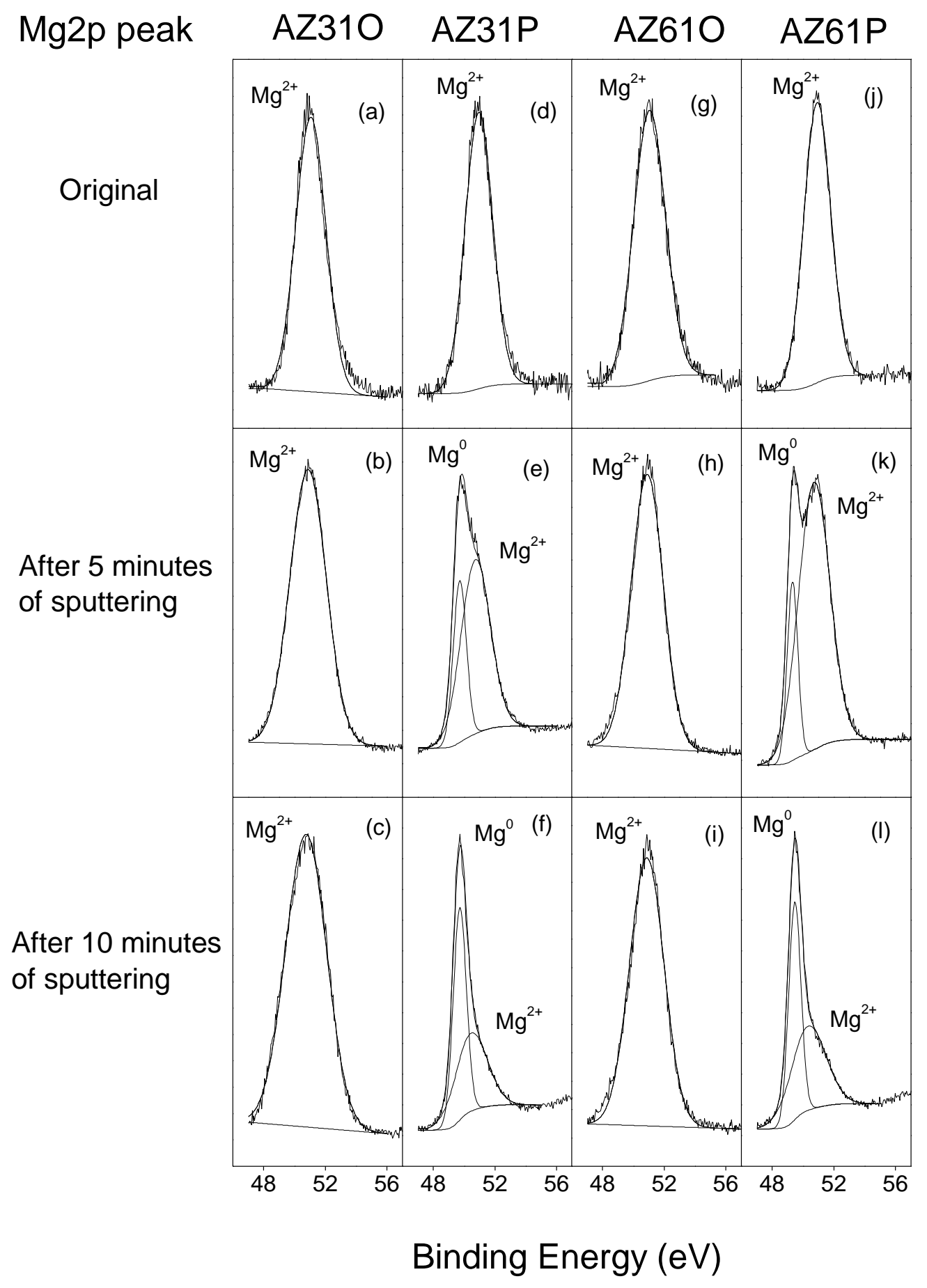

Figure 2 
AZ310

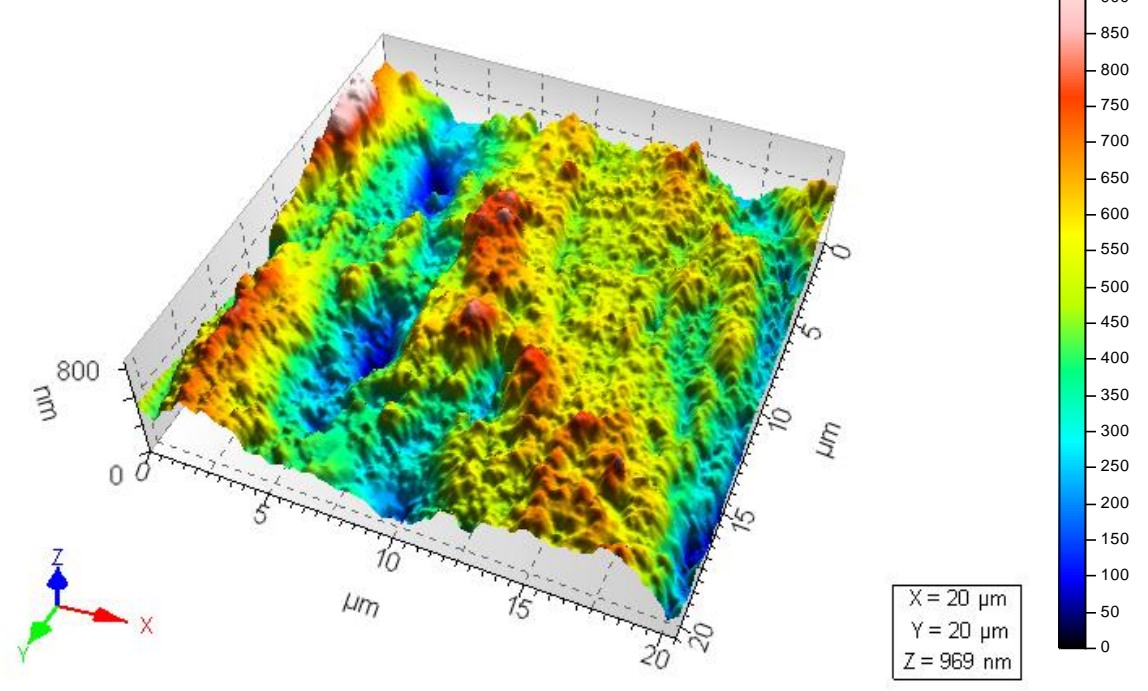

AZ31P
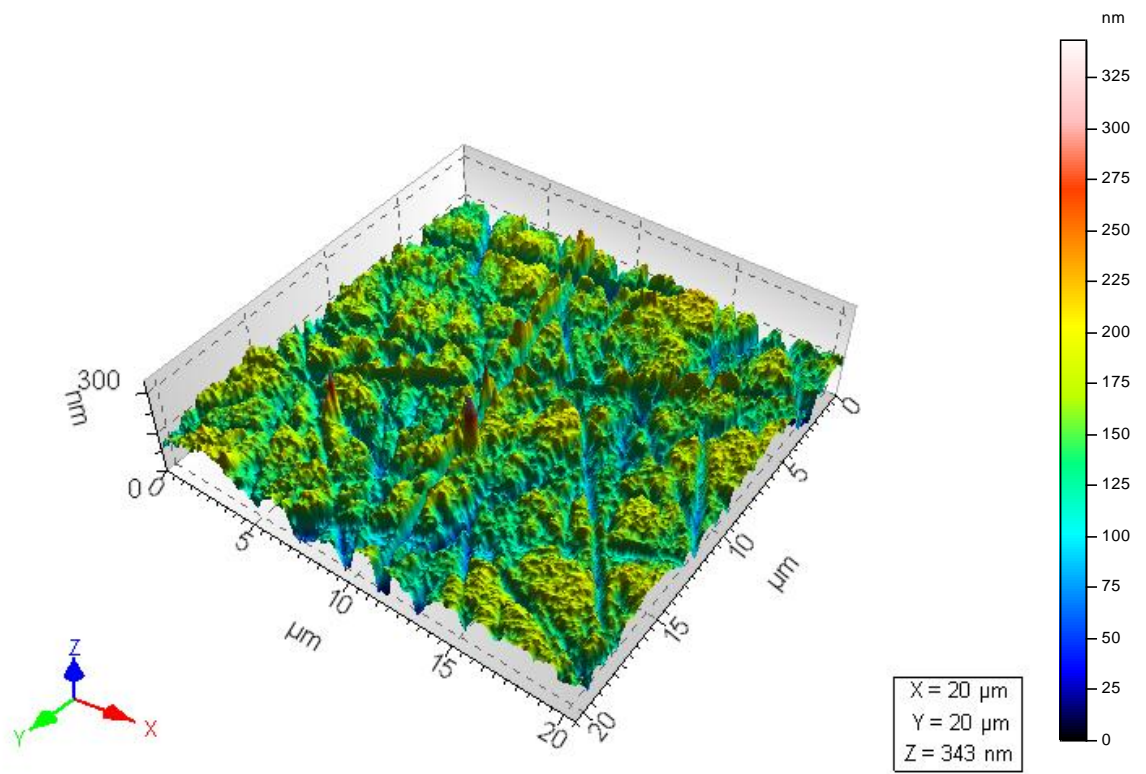

Fig 3 (a). 
AZ610

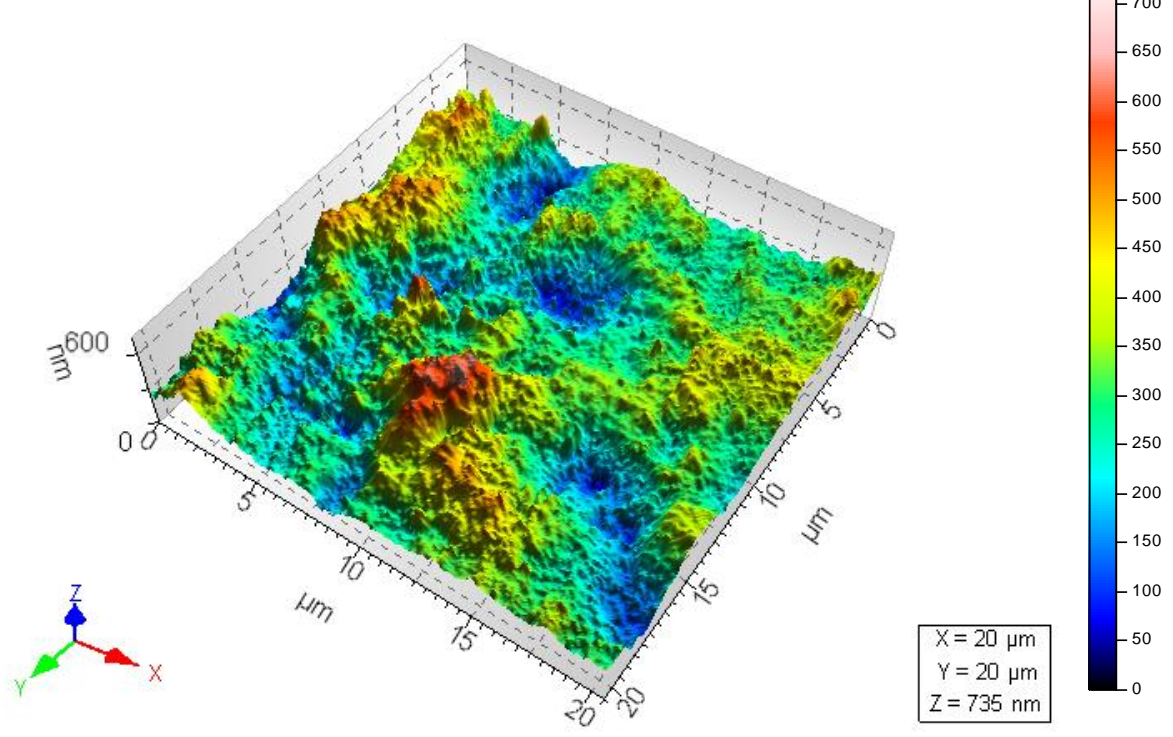

AZ61P


Fig. 3 b. 


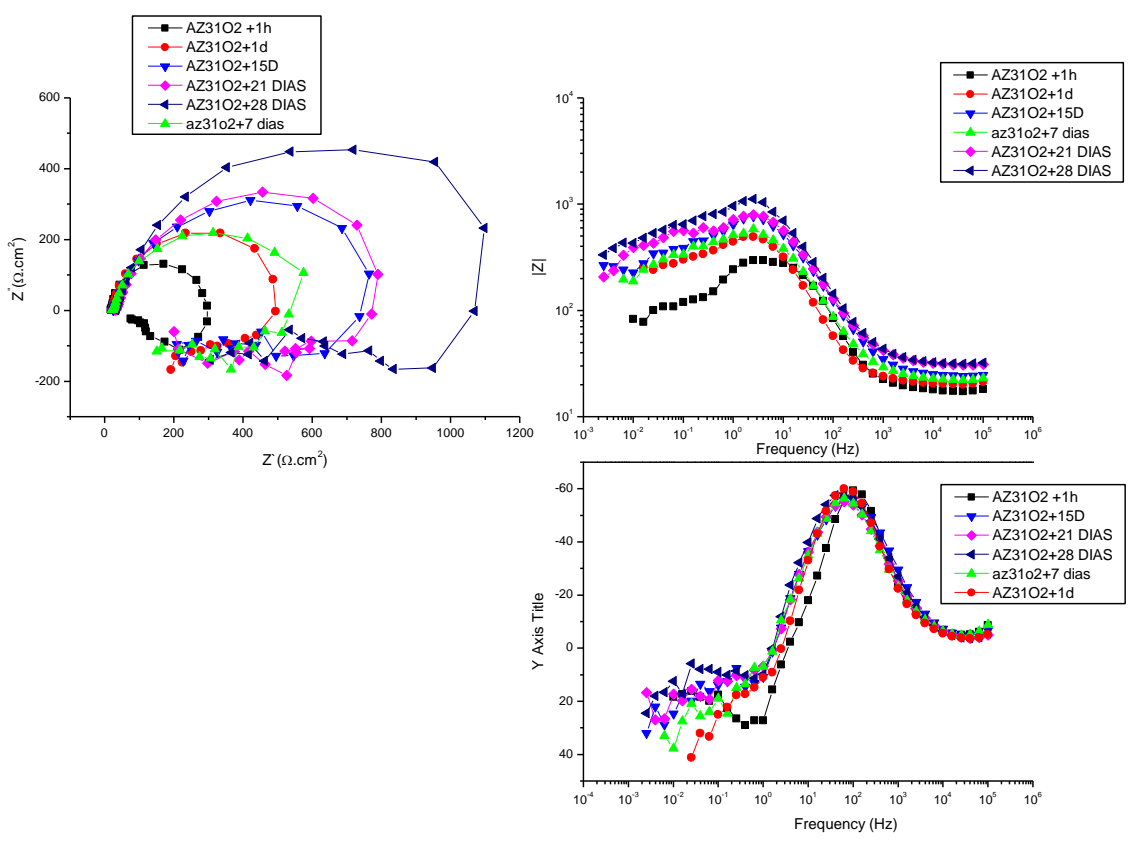

Figure 4a 


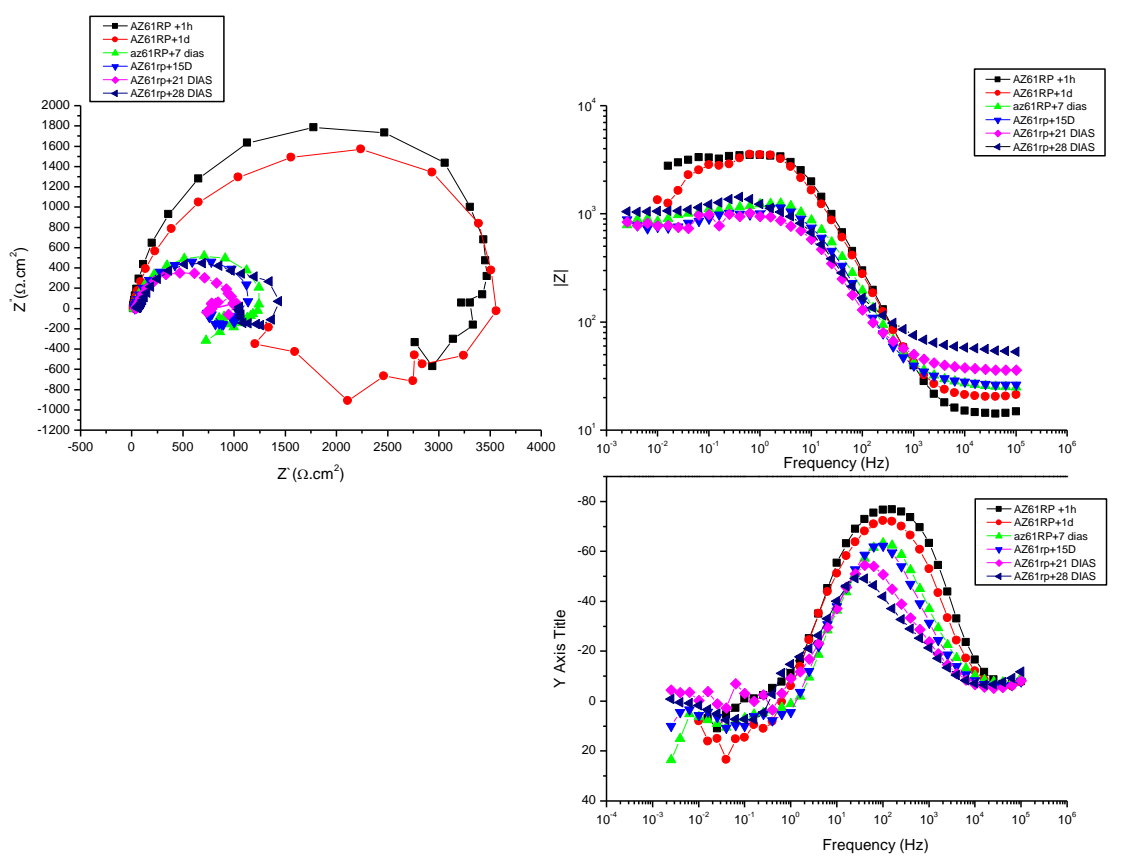

Fig 4b. 


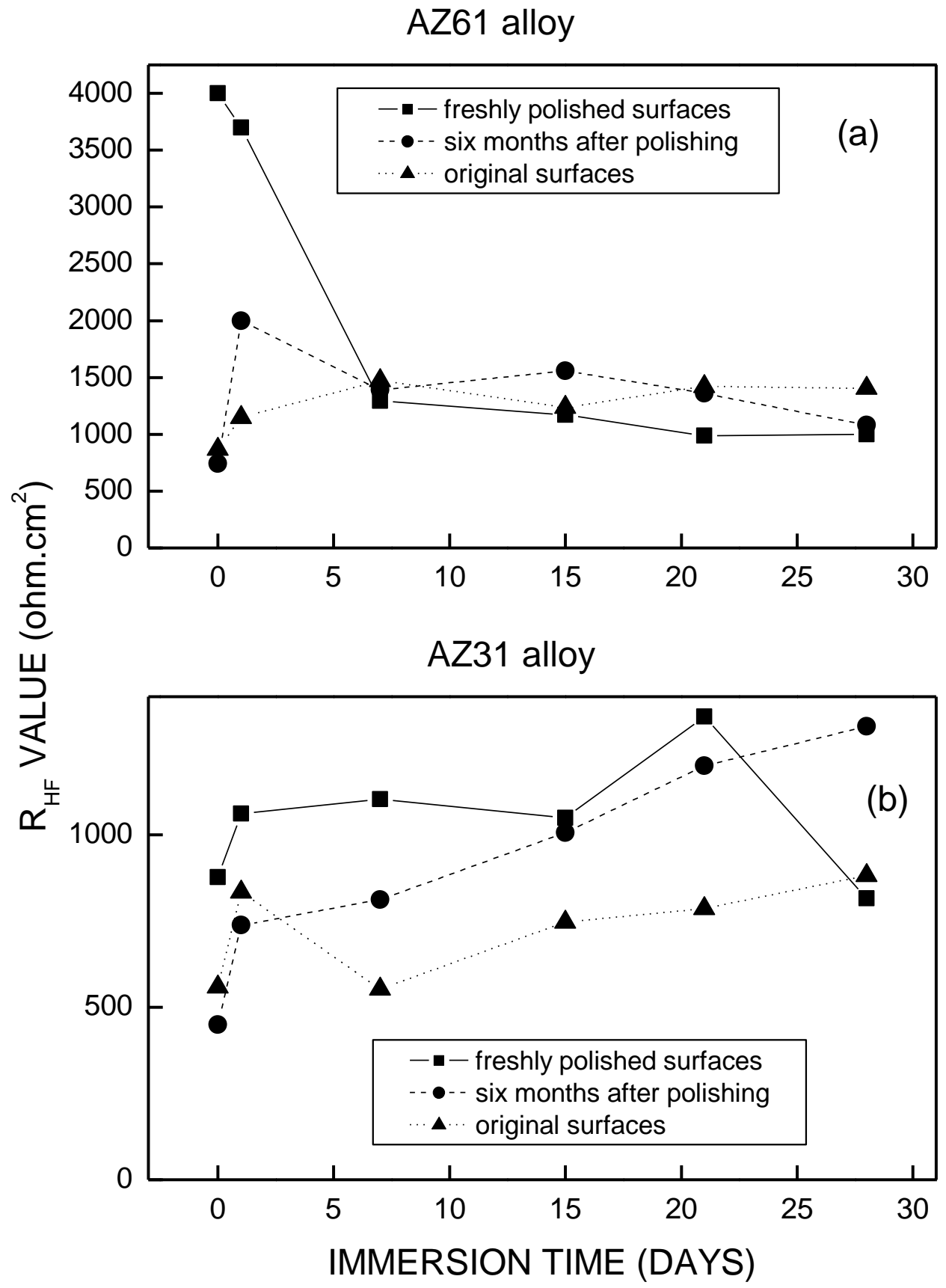

Fig. 5 


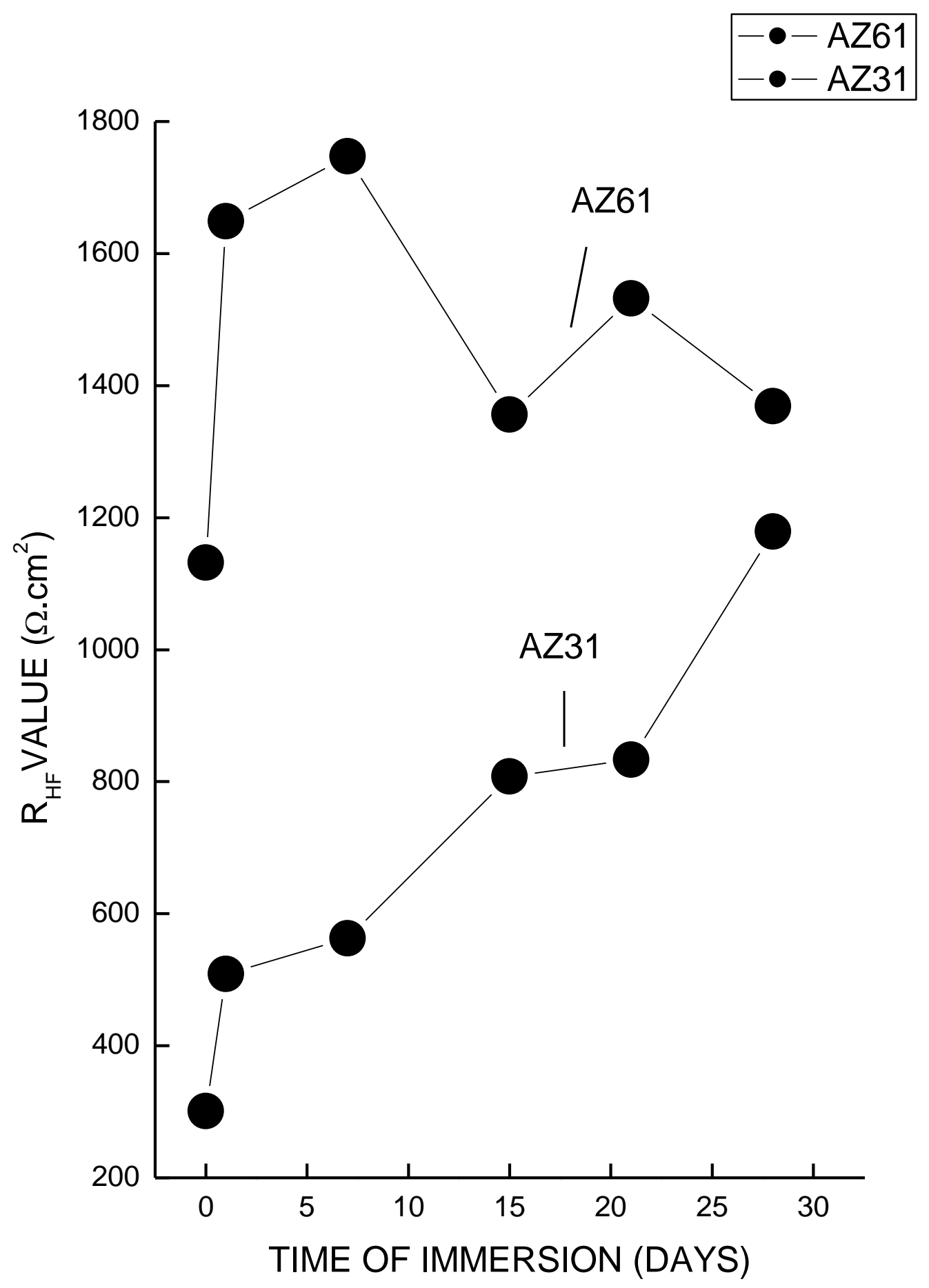

Fig. 6 


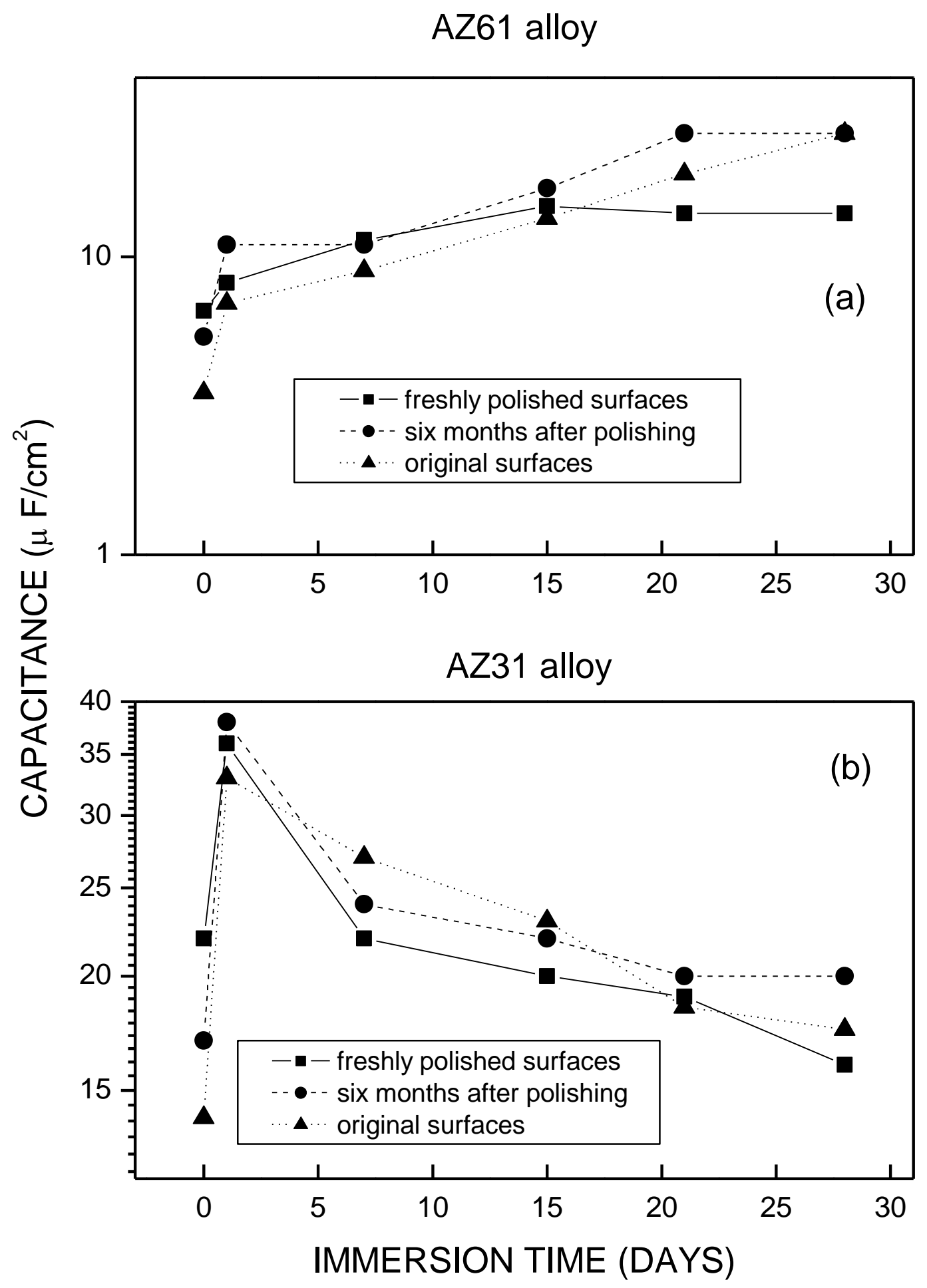

Fig. 7. 


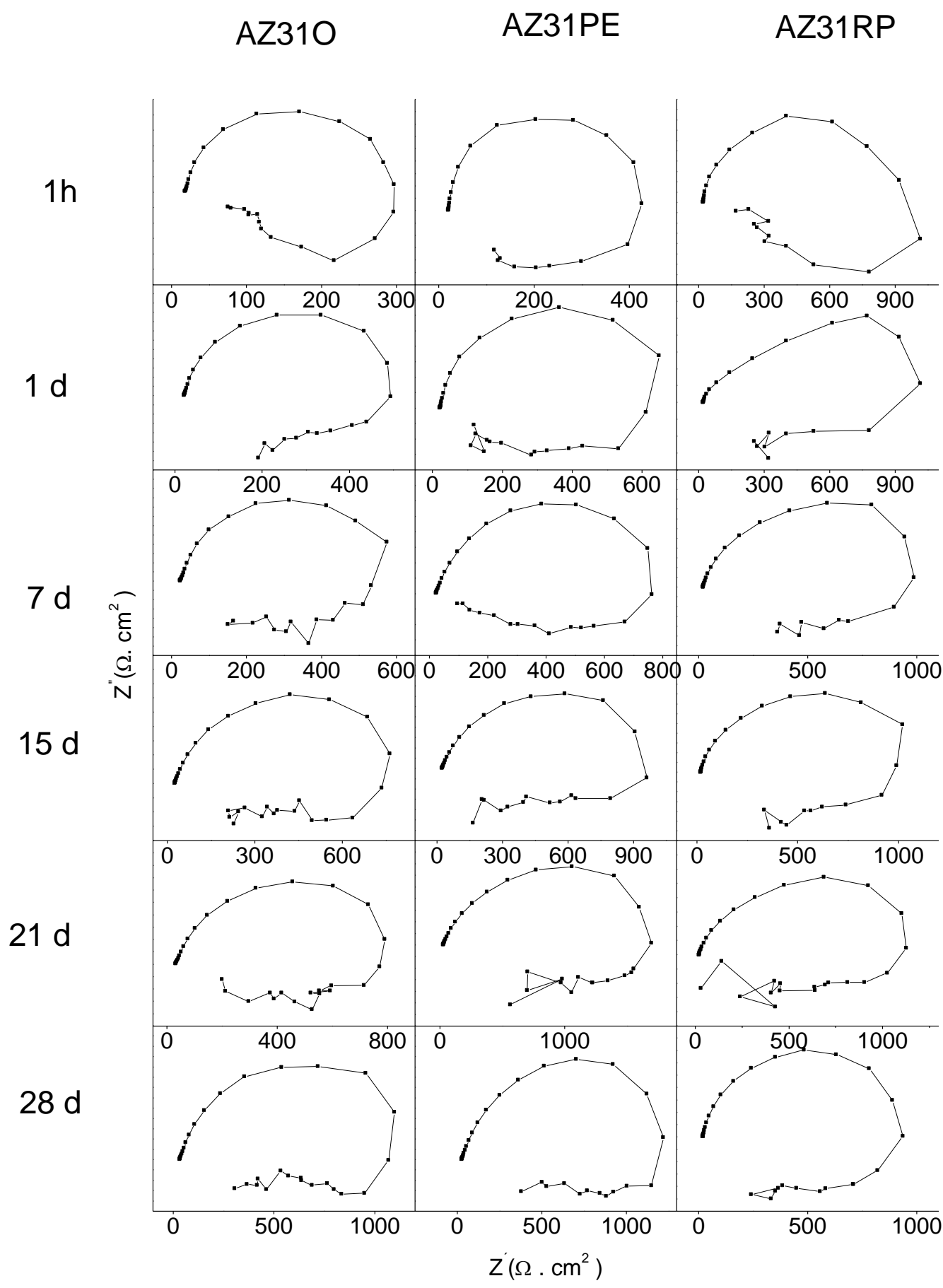

Fig 8 (a) 


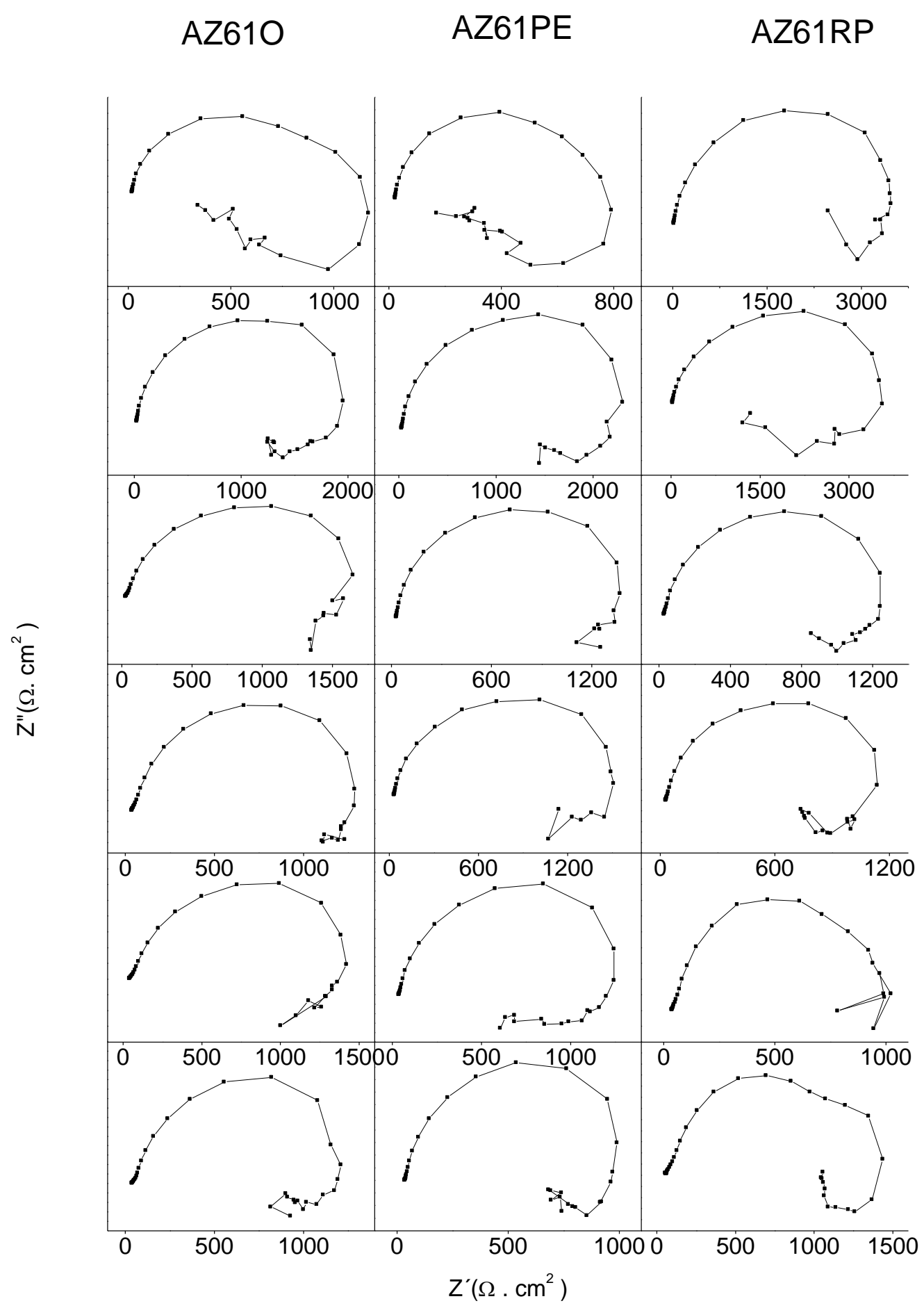

Fig $8 b$ 